\title{
Morphophysiological characters of Dendrobium var. Yellow Splash as influenced by bioinoculants and different levels of benzyladenine
}

\author{
*P. Shilpa, Mini Sankar, P.K. Sudhadevi, C.K. Geetha and Reshmi Vijayaraghavan \\ Department of Floriculture and Landscaping, College of Horticulture \\ Kerala Agricultural University, Thrissur. \\ *E-mail:-shilpaponnarath@gmail.com
}

\begin{abstract}
Dendrobium is the most commonly grown tropical orchid species in India and Kerala. They are highly specific about their nutrient requirement. The use of bio-inoculants in crop production of ornamentals has opened up a new possibility of using them for improving the growth and yield of orchids. Hence the objective of study was to evaluate the response of Dendrobium cv. Yellow Splash to different kinds of bio-inoculants viz., AMF, Azospirillum and a microbial consortia PGPR Mix - 1 developed from KAU, along with 50, 100 and 150 ppm of benzyladenine. The experiment consisted of ten different treatments involving bio-inoculants and benzyladenine. Plant height and number of leaves were maximum in the plants inoculated with AMF along with $100 \mathrm{ppm}$ benzyladenine. Treatment comprising of Azospirillum and 100 ppm benzyladenine was superior in terms of other morphological parameters like leaf breadth, leaf area and plant spread. Maximum leaf length and highest number of shoots were observed in plants inoculated with Azospirillumand $150 \mathrm{ppm}$ benzyladenine. Considering the floral parameters, both quantitative and qualitative attributes were found to be superior in the treatment consisting of AMF along with $150 \mathrm{ppm}$ benzyladenine. Highest root length was observed under the treatment AMF along with 100 ppm benzyladenine while number of roots and root volume were maximum in the plants inoculated with Azospirillum and $150 \mathrm{ppm}$ benzyladenine. Plants inoculated with AMF and 100 ppm benzyladenine had highest chlorophyll content while highest stomatal frequency was observed under the treatment Azospirillum and $100 \mathrm{ppm}$ BA. From the study it could be concluded that inoculation of Dendrobium orchids with bio-inoculants like AMF and Azospirillum can significantly improve the morphological characters of the plants which in turn influence the production of quality spikes.
\end{abstract}

Keywords: Bio inoculants, benzyl adenine, AMF, Azospirillum and PGPR Mix - 1

\section{INTRODUCTION}

Orchids are elegant cut flowers that capture the title of 'highest selling flower' in Indian cut flower industry due to their unique shape, size, colour and characteristic aroma of certain species. Among the diversified species of orchids, Dendrobium is most commonly grown species in India, especially in Kerala. Commercial growers of Dendrobium in Kerala are facing many problems including inclement weather, pest and disease attack as well as lack of technical knowhow. They are unaware about the scientific nutrient management practices and their injudicious way of nutrient application leads to a decline in crop yield, higher incidence of pests and diseases and this will affect the production of export quality flowers. Commercial formulations of bio-inoculants have found to be widely used in crop production programmes of various ornamentals. Application of exogenous growth hormones has also been reported to increase the yield and quality attributes in ornamental crops. There is a need to develop a package which integrates the benefits from all possible sources of organic, inorganic and biologic components which can be recommended to orchid growers. Hence the present study was conducted with the objective of evaluating the response of Dendrobium var. Yellow Splash to bioinoculants and different levels of benzyl adenine. 


\section{MATERIAL AND METHODS}

The study was conducted in the Department of Floriculture and Landscaping, College of Horticulture, Vellanikkara, KAU. The experiment consisted of ten different treatments with three replications laid out in CRD. The adhoc nutrient recommendation for orchids as per Package of Practices recommendations of KAU is foliar application of $\mathrm{N}: \mathrm{P}, \mathrm{O} \ldots: \mathrm{K}, \mathrm{O}, 3: 1: 1$ during period of vegetative growth and 1:2:2 during flowering period at the rate of 0.2 per cent twice a week. Three bioinoculants viz., PGPR Mix - 1, AMF and Azospirillum and three levels of benzyladenine viz., 50, 100 and $150 \mathrm{ppm}$ were superimposed on this recommendation.

PGPR Mix-1 was applied through root dipping of plants in loose water slurry at the rate of $500 \mathrm{~g} / 2.51$ of water for 20 minutes prior to planting. AMF was directly applied at the rate of $50 \mathrm{~g} / \mathrm{kg}$ of potting media at the time of planting. Likewise, Azospirillum was applied through root dipping of plants in a slurry of $500 \mathrm{~g}$ of the inoculum in $50 \mathrm{ml}$ of water for 30 minutes prior to planting. Benzyl adenine (BA) was applied as foliar at monthly intervals.

\section{Treatments:}

$$
\begin{aligned}
& \text { T - POP + PGPR Mix-1 + BA } 50 \text { ppm } \\
& \text { T, - POP + PGPR Mix-1 + BA } 100 \text { ppm } \\
& \text { Tf - POP + PGPR Mix-1 + BA } 150 \text { ppm } \\
& \mathrm{T},-\mathrm{POP}+\mathrm{AMF}+\mathrm{BA} 50 \mathrm{ppm} \\
& \mathrm{T} \ldots \text {. } \mathrm{POP}+\mathrm{AMF}+\mathrm{BA} 100 \mathrm{ppm} \\
& \mathrm{T} \dagger-\mathrm{POP}+\mathrm{AMF}+\mathrm{BA} 150 \mathrm{ppm} \\
& \mathrm{T} \ddagger \text { - POP + Azospirillum + BA } 50 \text { ppm } \\
& \mathrm{T}^{\wedge} \text { - POP + Azospirillum + BA } 100 \text { ppm } \\
& \text { T\%o - POP + Azospirillum + BA } 150 \text { ppm } \\
& \mathrm{T} € \text { - Control (KAU POP recommendation for }
\end{aligned}
$$

\section{RESULTS AND DISCUSSION}

\section{Morphological parameters}

\section{Vegetative characters}

A significant improvement in vegetative characters were observed in treatments consisted of bio-inoculants and benzyladenine when compared to control(Table 1). Treatments consisted of AMF along with different concentrations of BA were superior in terms of plant height and maximum plant height was observed in T... (POP + AMF + BA 100 ppm). Increased plant height of AMF inoculated plants may be due to efficient endomycorrhizal association of the fungus with roots of Dendrobiumorchids which might have helped in better uptake and mobilization of nutrients. The mycorrhizal extrametrical hyphal strands extend into the medium, absorb water and minerals effectively and make it available to the plants. Better availability of nutrients along with the production of phytohormones and antibiotics might be contributed to the morphological and physiological changes resulting a significant improvement of plant height in plants inoculated with AMF. An improvement of plant height as a result of AMF inoculation has been reported in various flower crops (Varshneyet.al., 2002; Prabhat et al., 2003; Bhatia and Guptha, 2007)

A perusal of the data with respect to other vegetative characters like plant spread, number of leaves, leaf length, leaf breadth, leaf area and number of shoots per plant revealed that there was a significant improvement of all these parameters in plants inoculated with Azospirillumalong with different levels of BA and maximum values for all these parameters were observed in T\%o (POP + AMF + BA 150 ppm). Beneficial effect of Azospirilum might be the result of versatile mechanisms like increased nutrient uptake, enhanced stress resistance, vitamin production, siderophores and biocontrol, operating simultaneously or sequentially in Azospirillum inoculated plants (Cohen et al., 2015). Azospirillum species are having the capacity of self-production of phytohormones like auxin, gibberlins, cytokinins and nitric oxide and inducing the synthesis of these compounds in plant tissues (Gadagi, 1999). Cytokinin regulates several processes such as cell division, leaf expansion, shoot and root morphogenesis. Gibberlins are responsible for cell division and elongation of plant cells. Azospirillum present in the rhizosphere are able to produce 


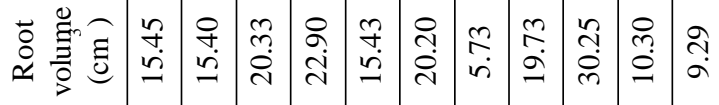

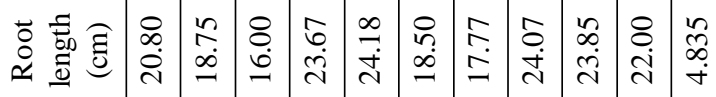

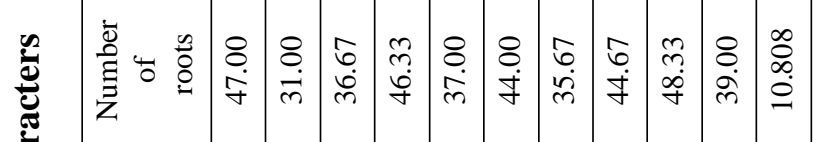

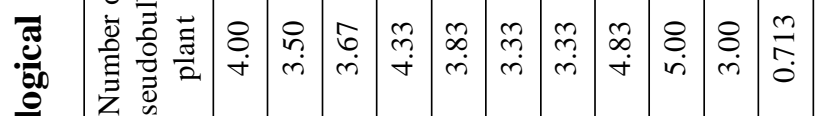
믈

בั

胥

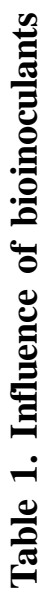

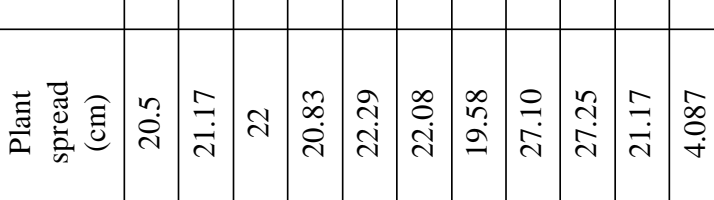

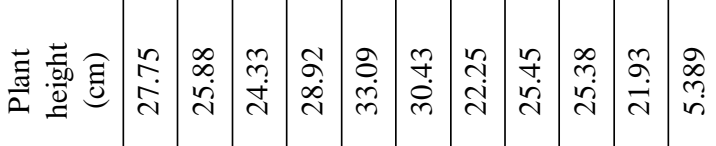

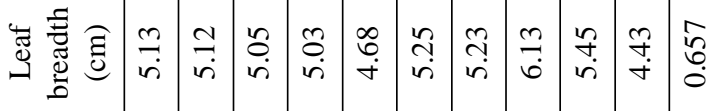

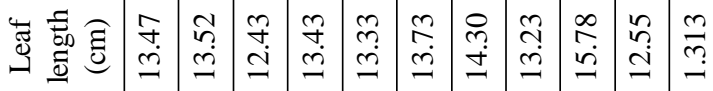

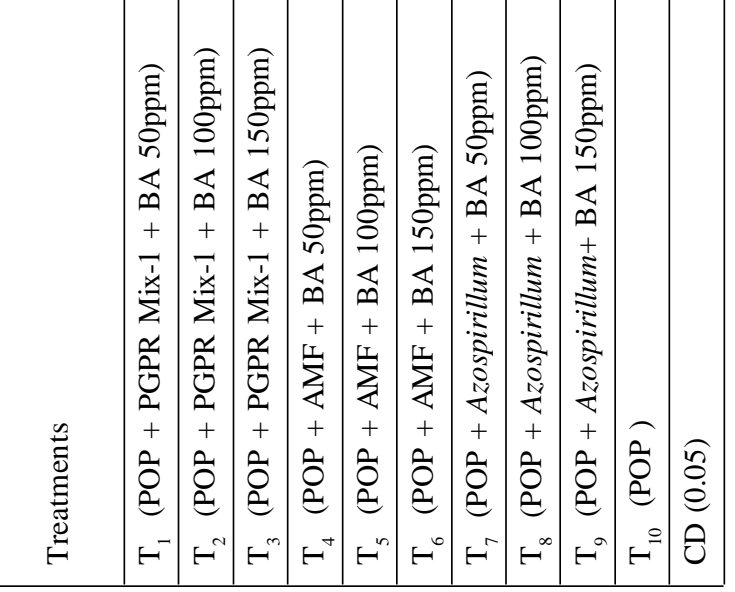

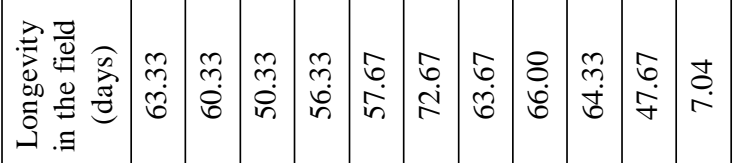

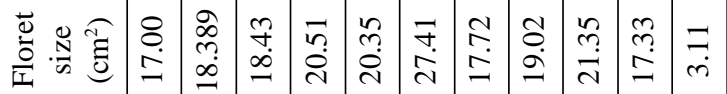

茪

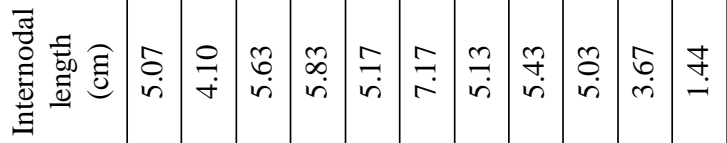

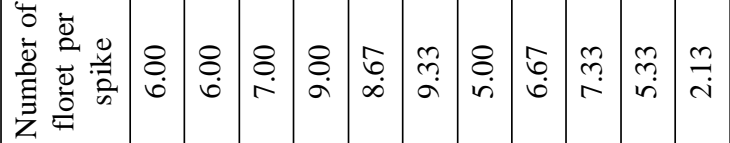

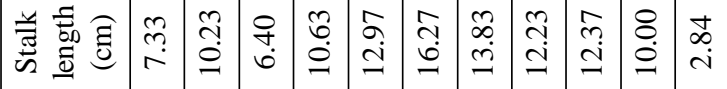

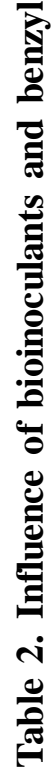

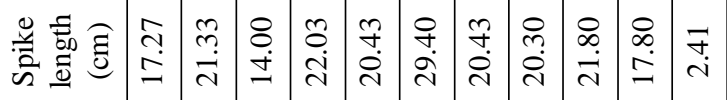

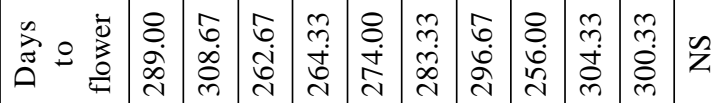

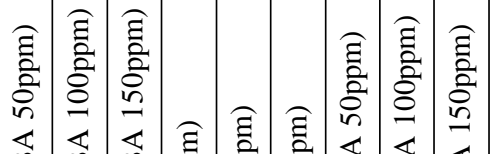

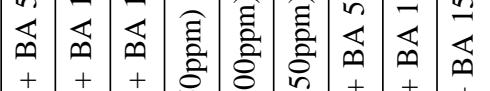

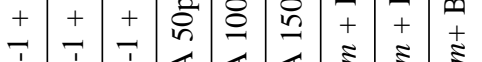

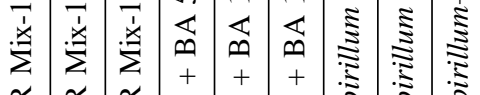
些

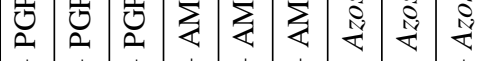

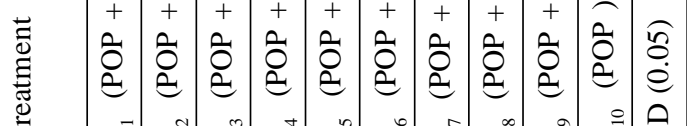

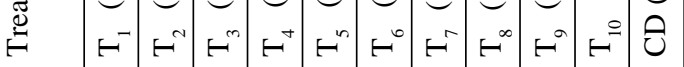


metabolites which act as signals for the production of phytohormones in the plant system. Action of phytohormones like cytokinins and gibberlins coupled with increased nutrient status of Azospirillum inoculated plants might have contributed to the improvement of vegetative characters like plant spread, leaf length, breadth and leaf area. These results are in conformity with findings of Bhaskar et al. (2002) in marigold, Anon. (2003) in Dendrobium, Srinivasa (2006), Chaudhary et al. (2013) in gladiolous, Hoda and Mona (2014) in petunia and Yadav et al. (2013) in gerbera, who reported an improvement in vegetative growth as a result of Azospirillum inoculation.

In both the cases of inoculation with AMF and Azospirillum, optimistic results were obtained when the plants were supplied with benzyladenine along with these bio-inoculants. Benzyladenine is characterised as a synthetic cytokinin which highly helps in the cell division, cell elongation, organ formation and regeneration and also they play an important role in translocation of assimilates to growing cells. Application of exogenous cytokinin has been reported to increase the synthesis of endogenous cytokinin in plants (Letham, 1994). In the present study the exogenous application of benzyladenine might have increased the level of cytokinin in the plants. Elevated cytokinin level and morphophysiological changes due to bio-inoculant treatments might have resulted an improvement of vegetative growth in plants under these treatments.

\section{Root parameters}

From the results obtained, it could be clearly observed that, maximum root length was exhibited by the plants inoculated with AMF. This result might be mainly attributed to higher phosphorous uptake in the plants by extra radical mycelium leading to higher shoot and root growth in inoculated plants (Smith and Read, 1997). AMF was reported to produce metabolites that can alter the plant's ability to produce roots and to alter root regeneration and root morphology resulting an increased absorptive surface area and feeder root longevity (Linderman, 1988). A diffusible symbiotic signal produced by AMF which is recently identified as lipochito oligosaccharides (LCOs), designated as My factors which helps in root growth and branching (Maillet et al., 2011) could be considered as another reason for the high rate of root growth in AMF inoculated plants. This result is in accordance with the findings of Martin and Stutz (2004); Perner et al. (2007).
In the case of number of roots and root volume, higher number of roots and maximum root volume were produced by the plants under the treatment $\mathrm{T} \%$ o (POP + Azospirillum $+150 \mathrm{ppm} \mathrm{BA})$. Azospirillum is a gram negative diazotrophicrhizobacteria which exhibits chemotactic response to plant exudates, i.e., the ability to sense and navigate towards the most favourable niches for growth (Rodriguezet al., 2009). When plants are inoculated with Azospirillum, the signalling molecules will be produced by the bacteria and the plant will produce lateral roots and root hairs which are the source of exudates to maintain bacterial population in rhizosphere (Gadagiet al., 2004). Significant changes in the root volume and number of roots were reported as a result Azospirillum inoculation in different cereals (Wani, 1990 and Okonand Itzigsohn, 1995). Production and secretion of phytohormones like auxin, cytokinin and gibberlins by Azospirillum itself might be the reason for more number of root formations in the inoculated plants. Similar findings were reported by Molla et al. (2001) and Remans et al. (2008)

In different root parameters considered, bioinoculants along with 100 and 150 ppm benzyladenine exhibited maximum values for all the root characters. Even though benzyladenine has least effect on root growth, sometimes through auto inductive cytokinin regulation, this effect may reverse, favouring better root production in the plants. So here in addition to the phytohormone produced inside the plant due to Azospirillum inoculation, exogenous application of BA might have elevated the level of cytokinin concentration within the plants and higher root production might have occurred due to autoinductivecytokinin regulation. Similar findings were also reported by Wroblewska (2013).

\section{Floral characters}

An improvement in the parameters like length of the spike, stalk length, number of flowers per spike, flower sizeand field life of spikes were observed in the treatments consisting of AMF in combination with different levels of benzyl adenine(Table 2). However the treatment $\mathrm{T} \dagger(\mathrm{POP}+\mathrm{AMF}+\mathrm{BA} 150 \mathrm{ppm})$ was found to be the best among all the treatments. Even though epiphytic orchids like Dendrobiumare characterised by the presence of ariel roots covered with velamen tissue, itcan be function as absorbing roots, once it gets attached to a substrate (Dycus et 
$a l ., 1957)$. Hence in addition to the nutrients supplied through foliar spray, there might have been an additional exploration of nutrients, especially phosphorous, from the growing substrate also. The positive influence of AMF inoculated plants in floral characters might be due to this enhanced absorption and availability of nutrients to the plants combined with efficient translocation of phytohormones resulting in early flower initiation and production of quality spikes.

Benzyladenine, a synthetic reported to be one of the multifactorial components that functions as floral stimulus and exogenous application of cytokinin was reported to hasten the rate of flower initiation and flower production due to an increase in endogenous level of cytokinin in plant system (Blanchard and Runkle, 2008). The result of the study is in conformity with the findings of Perner et al., (2007)and Barman et al., (2014) who reported a positive influence of benzyladenine on floral characters in various flower crops.

\section{Physiological parameters}

\section{Chlorophyll content}

Regarding chlorophyll content, maximum chl a, chl b and total chlorophyll content were observed in the treatment $\mathrm{T}$... (POP + AMF +100 ppm benzyladenine $)$ Fig. 1. This might be due to an elevated level of stomatal conductance, transpiration, photosynthesis and plant growth. Formation of larger and more number of bundle sheath chloroplast could be another reason for maximum production of chloroplast in inoculated plants (Arumugan et al., 2010).

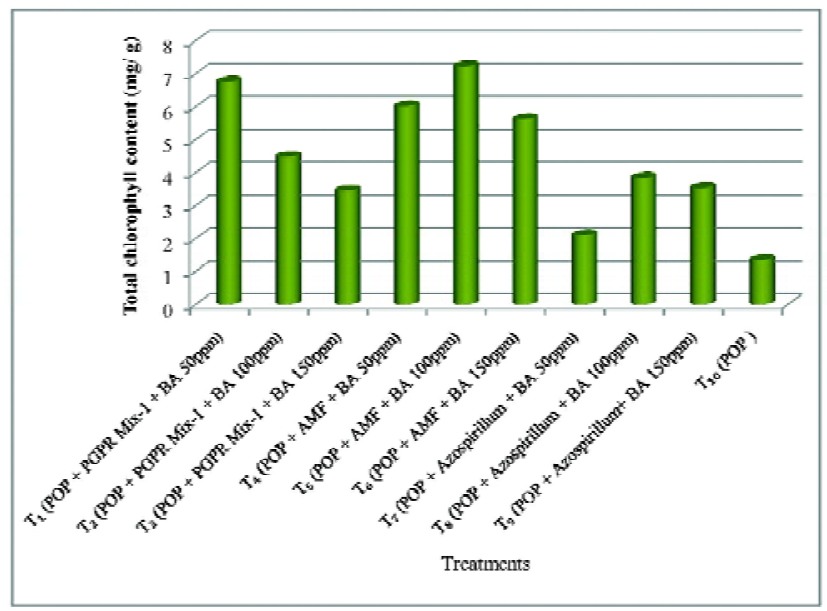

Fig 1. Influence of bioinoculants and benzyl adenine on total chlorophyll content
In addition to the effect of AMF, benzyladenine also carries an important role for higher chlorophyll production in the plants under this treatment (T...). Cytokinin encourage the protease activity and results in the release of cations like $\mathrm{Ca}^{2} \mathrm{z}, \mathrm{Mg}^{2} \mathrm{z}$ and $\mathrm{Zn}^{2} \mathrm{z}$ from their nature bound or complexed state (Fletcher et al., 1971) and the release of these ions may also be the possible reason for higher chlorophyll production in this treatment. The result of the present study is found to be in accordance with the findings of Fletcher and McCullagh (1971).

\section{Stomatal characters}

Considering the stomatal frequency, maximum number of stomata was obtained in the treatment consisted of Azospirillum and 100 ppm benzyladenine applied along with the recommended dose of NPK and cow dung slurry (POP)(Fig.2). Since the maximum leaf area was observed in the same treatment, it could be the reason for more number of stomata compared to other plants.

\section{CONCLUSION}

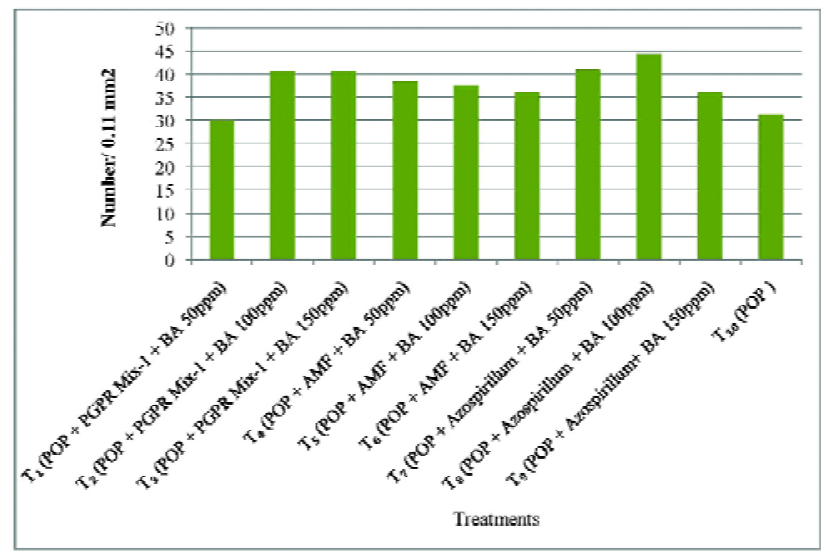

Fig 2. Influence of bioinoculants and benzyl adenine on stomatal density

From the study it could be observed that there was a significant improvement in the vegetative as well as root parameters in the treatment consisting of Azospirillum along with 100 and $150 \mathrm{ppm}$ benzyladenine. However the treatment $\mathrm{T} \dagger(\mathrm{POP}+$ AMF along with $150 \mathrm{ppm}$ benzyladenine) was found to be superior in both qualitative and quantitative floral attributes. Since the orchids an grown for their high value cut spikes, the treatment $\mathrm{T}_{6}(\mathrm{POP}+\mathrm{AMF}+150$ ppm BA) can be recommended for production of quality spikes in Dendrobium orchids. 


\section{REFERENCE}

[Anonymous]. 2003. Orchids. Biennial Progress Report, Indian Council of Agricultural Research, New Delhi, pp. $204-243$.

Arumugam, R., S. Rajasekaran and S.M. Nagajan. 2010. Response of Arbuscularmycorrhizal fungi and Rhizobium inoculation on growth and chlorophyll content of Vignaunguiculata (L) Walp Var. Pusa 151. J. Appl. Sci. Environ., Manage.14(4):113-115.

Barman, D., Usha Bharathi, T., Pokhrel, H., Naik, S. K. and Medhi, R. P. 2014. Influence of concentration and mode of application of different growth regulators on Dendrobiumhybrid Thongchai Gold. J. Crop Weed. 10(3): 223 - 230.

Bhaskar, P., Ambrose, G., and Jayabalan, N. 2002. Usefulness of biofertilizers in economizing nitrogenous fertilizers in TageteserectaL. $J$. Phytological Res. 15(2): 155-160.

Bhatia, S. and Gupta, Y. C. 2007. Studies on use of biofertilizer in carnation (Dianthus caryophyllusLinn.) flower production. J. Ornamental Hortic. 10(2): 131-132.

Blanchard, M. G. and Runkle, E. S. 2008. Benzyl adenine promotes flowering in Doritaenopsisand Phalaenopsisorchids. J. Plant Growth Reg. 27(2): 141 - 150.

Chaudhary, N., Swaroop, K., Janakiram, T., Biswas, D. R., and Singh, G. 2013.Effect of integrated nutrient management on vegetative growth and flowering characters of gladiolus.Indian J. Hort. 70(1): 156-159.

Cohen, A. C., Bottini, R., Pontin, M., Berli, F. J., Moreno, D., Boccanlandro, H. and Piccoli, P. N. 2015. Azospirillumbrasilens eameliorates the response of Arabidopsis thaliana to drought mainly via enhancement of ABA levels.Physiol.plant.153 (1): 79-90.

Dycus, Augustus M., and Lewis Knudson. 1957. The role of the velamen of the aerial roots of orchids. Bot. Gazette. 119(2): 78-87
Fletcher, R. A., and McCullagh, D. 1971.Benzyladenine as a regulator of chlorophyll synthesis in cucumber cotyledons.CanadianJ.Bot.49(12): 21972201

Gadagi, R. 1999. Studies on Azospirillum isolates of ornamental plants and their effect on Gaillardia pulchellavar. picta. Fouger. M.Sc. (Ag) Thesis, University of Agricultural Sciences, Dharwad, 72p.

Gadagi, R. S., Krishnaraj, P. U., Kulkarni, J. H., andSa, T. (2004).The effect of combined Azospirillum inoculation and nitrogen fertilizer on plant growth promotion and yield response of the blanket flower Gaillardia pulchella.Sci.Hort.100 (1): 323-332.

Hoda, E. and Mona, S. 2014. Effect of bio and chemical fertilizers on growth and flowering of Petunia hybridaplants.Amer. J. Plant Physiol. 9: 68-77.

Letham, D. S. 1994. Cytokinins as phytohormonessites of biosynthesis, translocation and function of translocated cytokinin. Cytokinins: chemistry, activity and function, pp. 57-80.

Linderman, R. G. 1988. Mycorrhizal interactions with the rhizospheremicroflora: the mycorrhizosphere effect. Phytopathol. 78(3): 366-371.

Maillet, F., Poinsot, V., Andre, O., Puech-Pagès, V., Haouy, A., Gueunier, M., Cromer, L., Giraudet, D., Formey, D., Niebel, A. and Martinez, E.A. 2011.Fungal lipochitooligosaccharide symbiotic signals in arbuscularmycorrhiza. Nature. 469(7328): p.58.

Martin, C. A. and Stutz, J. C. 2004.Interactive effects of temperature and arbuscularmycorrhizal fungi on growth, $\mathrm{P}$ uptake and root respiration of Capsicum annuum L. Mycorrhiza. 14(4): 241-244. 
Molla, A. H., Shamsuddin, Z. H., and Saud, H. M. 2001. Mechanism of root growth and promotion of nodulation in vegetable soybean by Azospirillum brasilense. Commun. Soil Sci. Plant Anal. 32: 2177-2187.

Okon, Y. and Itzigsohn, R. 1995. The development of Azospirillumas a commercial inoculant for improving crop yields. Biotechnol. Advances. 13(3): 415-424.

Perner, H., Schwarz, D., Bruns, C., Mäder, P., and George. 2007. Effect of arbuscularmycorrhizal colonization and two levels of compost supply on nutrient uptake and flowering of pelargonium plants.Mycorrhiza. 17(5): 469-474.

Prabhat. K., Raghava, S. P. S. and Misra, R. L. 2003.Effect of biofertilizers on growth and yield of China aster.J. Ornamental Hortic.6(2): 85-88.

Remans, R., Beebe, S., Blair, M., Manrique, G., Tovar, E., Rao, I. and Vanderleyden, J. 2008. Physiological and genetic analysis of root responsiveness to auxin-producing plant growth-promoting bacteria in common bean (Phaseolus vulgaris L.). Plant and soil. $\mathbf{3 0 2}$ (2): 149-161.

Rodriguez-Salazar,J., Suárez, R., Caballero-Mellado, J., and Iturriaga, G. 2009. Trehalose accumulation in Azospirillumbrasilense improves drought tolerance and biomass in maize plants. FEMS Microbiol. Letters. 296(1): 52-59.

Smith, S. E. and Read, D. J. 1997. Mycorrhizal symbiosis 2.ed. Academic, London, 605p

Srinivasa, V. (2006).Effect of Media on Growth and Flowering of Anthuriumandreanum. Environ. and Ecol. 24(2), 257p

Varshney, A., Sharma, M. P., Adholeya, A., Dhawan, V. and Srivastava, P. S. 2002. Enhanced growth of micro propagated bulblets of Liliumsp. inoculated with arbuscular mycorrhizal fungi at different $\mathrm{P}$ fertility levels in an alfisol. The J. Hortic. Sci. and Biotechnol. 77(3): 258-263.

Wani, S.P. 1990. Inoculation with associative nitrogen fixing bacteria: role in cereal grain production improvement. Indian $J$. Microbiol.,30: 363-393.

Wroblewska, K. 2013. Benzyl adenine effect on rooting and axillary shoot outgrowth of Gauralindheimeri Engelm. A. Gray cuttings. Acta. Scientiarum. Polonorum. HortorumCultus. 12(3): 127 - 136.

Yadav, K., Aggarwal, A. and Singh, N. 2013. Arbuscularmycorrhizal fungi induced acclimatization and growth enhancement of GlycyrrhizaglabraL: a potential medicinal plant. Agric. Res. 2(1): 43-47.

(MS Received 26 October2017, Revised 15 February 2018, Accepted 27June 2018) 